\title{
SLAMS - LETRAMENTOS LITERÁRIOS DE REEXISTÊNCIA AO/NO MUNDO CONTEMPORÂNEO
}

\section{POETRY SLAMS - LITERACY LITERACIES OF REEXISTENCE IN/TO THE CONTEMPORARY WORLD}

\author{
Cynthia Agra de Brito Neres* \\ Universidade Estadual de Campinas, Campinas, SP, Brasil
}

\begin{abstract}
Resumo: Um novo fenômeno de poesia oral e performática cresce no mundo contemporâneo: são os chamados slams - competições ou batalhas de poesias que dão vez e voz a poetas da periferia, os quais versam sobre as adversidades do seu cotidiano, abordando temas como racismo, violência, drogas, machismo, sexismo, sempre de teor crítico e engajado, que requerem a escuta, a reflexão e a politizacãão do seu público- ouvinte. Os slammers incorporam as "vozes das margens" (HALL, 2003), as "vozes do Sul" (MOITA LOPES, 2006) ou as "vozes do corpo" (DE CERTEAU, 1994) e, nos palcos, atuam como agentes de letramentos de reexistência (SOUZA, 2011) ao declamarem poesias de sua própria autoria para cinco jurados escolhidos da plateia pelos organizadores do slam. Ao vencedor(a), livros!
\end{abstract}

Palavras-chave: slam; slammer; poesia oral; poesia performática; letramentos de reexistência.

Abstract: A brand new phenomenon of oral and performative poetry known as slam is currently flourishing. It is a competition in which poets from the suburbs have their voices to be heard and remark everyday adversities in a socially engaged way. Addressing themes such as racism, violence, drugs, chauvinism, and sexism, those battles require a politicized audience, a listening and an active thinking. The slammers incorporate "voices from the margin" (HALL, 2003), "from the South" (MOITA LOPES, 2006), or "from the body" (DE CERTEAU, 1994). Moreover, by reciting authorial poems to a panel of five judges chosen among members of the audience, slammers became agents of a literacy of re-existence (SOUZA, 2011). The winner takes the books!

Keywords: Slam; Slammer; Oral poetry; Performative poetry; Literacy of Re-existence.

* Professora da Universidade Estadual de Campinas - Unicamp, Campinas, SP, Brasil; cynneves@iel.unicamp.br 
Linha D'Água (Online), São Paulo, v. 30, n. 2, p. 92-112, out. 2017

\section{Introdução}

A palavra slam é uma onomatopeia da língua inglesa utilizada para indicar o som de uma "batida" de porta ou janela, seja esse movimento leve ou abrupto. Algo próximo do nosso "pá!" em língua portuguesa. A onomatopeia foi emprestada por Marc Kelly Smith, um trabalhador da construção civil e poeta, para nomear o $U_{p}$ town Poetry Slam, evento poético que surgiu em Chicago, em 1984. O termo slam é utilizado para se referir às finais de torneios de baseball, tênis, bridge, basquete, por exemplo. Smith nomeou também de slam os campeonatos de performances poéticas que organizava e no qual os slammers (poetas) eram avaliados com notas pelo público presente, inicialmente, em um bar de jazz em Chicago, depois nas periferias da cidade. A iniciativa "viralizou", como se diz hoje, contagiando outras cidades dos Estados Unidos e, mais tarde, ganhou o mundo. Poesia é o mundo.

Poderíamos definir o poetry slam, ou simplesmente slam, de diversas maneiras: uma competição de poesia falada, um espaço para livre expressão poética, uma ágora onde questões da atualidade são debatidas ou até mesmo mais uma forma de entretenimento. De fato, é difícil defini-lo de maneira tão simplificada, pois, em seus 25 anos de existência, ele se tornou, além de um acontecimento poético, um movimento social, cultural, artístico que se expande progressivamente e é celebrado em comunidades em todo mundo. (D’ALVA, 2014, p. 109)

A definição é de Roberta Estrela D'Alva (2014), atriz-MC, diretora musical, pesquisadora, apresentadora de um programa juvenil na TV-Cultura de SP e afiliadas, e slammer (poetisa) brasileira. Foi ela quem trouxe o Poetry Slam para o Brasil, em dezembro de 2008, ao fundar o ZAP! Slam em São Paulo. D’Alva manteve a onomatopeia que, segundo ela, funciona como uma sigla para significar " $\mathrm{Zona} \mathrm{Au}$ tônoma da Palavra". Foi uma das fundadoras da primeira companhia de teatro hip hop do Brasil, o Núcleo Bartolomeu de Depoimentos, e da Frente Três de Fevereiro',

1 A Frente Três de Fevereiro é um grupo de pesquisa e de ação direta que, por meio de um trabalho multidisciplinar, busca discutir o racismo no Brasil, sobretudo o racismo policial. O grupo trabalha com artes visuais, teatro, poesia, audiovisual, aulas, debates e diversas outras formas expressivas, buscando investigar as raízes do preconceito racial no Brasil e promover ações para colocar o tema em destaque. O grupo publicou um livro Zumbi Somos Nós, em 2004, que 
Linha D'Água (Online), São Paulo, v. 30, n. 2, p. 92-112, out. 2017

além de colecionar diversos prêmios em seu currículo artístico ${ }^{2}$. A poetisa promove o ZAP! Slam toda primeira quinta-feira do mês, a partir das $20 \mathrm{~h}$, com exceção do mês de janeiro, em algum ponto central da cidade paulistana. É ainda curadora do Rio Poetry Slam, que acontece anualmente na Festa Literária das Periferias (FLUPP), no Rio de Janeiro. E foi finalista da Copa do Mundo de Poesia Falada de 2011, em Paris, na França, conquistando o terceiro lugar.

Em 2014 foi a vez de Emerson Alcalde ${ }^{3}$, poeta e ator, slammer desde 2008, conquistar o segundo lugar nessa Copa Mundial promovida anualmente na capital francesa. Em 2012, Alcalde fundou o Slam da Guilhermina, o segundo slam do Brasil, na Zona Leste de São Paulo. Os encontros poéticos acontecem todas as últimas sextas-feiras de cada mês, a partir das $20 \mathrm{~h}$, também com exceção do mês de janeiro, na praça Guilhermina-Esperança, ao lado da estação homônima do metrô, um lugar de estratégica visibilidade para os transeuntes. Em entrevista, Alcalde confessa ter se inspirado nas batalhas de $\mathrm{MCs}^{4}$, que tanto em

denuncia o racismo policial no Brasil.

Cf. em https://arteparaumacidadesensivel.wordpress.com/obras/frente-3-de-fevereiro/. Acesso em 30 mai. 2017.

2 Roberta D'Alva dirigiu o Cindi hip hop: pequena ópera rap, vencedor do prêmio FEMSA/ Coca de melhor espetáculo jovem e do prêmio Cooperativa de Teatro de melhor dramaturgia; ganhou o famoso Prêmio Shell de melhor atriz em 2012, pela sua atuação no espetáculo Orfeu mestiço: uma hip-hópera brasileira. Em novembro de 2014 foi publicado o seu primeiro livro Teatro Hip-Hop: a performance poética do ator-MC (Cf. Referências). Em 2016, a atriz foi dirigida pelo diretor americano Robert Wilson no espetáculo Garrincha - a street ópera. Atualmente, é apresentadora do programa Manos e Minas, que trata da cultura jovem e de rua, como o rap, o grafitti e o break, exibido semanalmente pela TV Cultura-SP e afiliadas. E está trabalhando na finalização do seu documentário Slam - Voz de Levante, co-dirigido por Tatiana Lohmman.

Cf. em https://pt.wikipedia.org/wiki/Roberta_Estrela_D\%27Alva. Acesso em 30 mai. 2017.

3 Emerson Alcalde foi entrevistado por mim no dia 16 de maio, às $14 \mathrm{~h} 30$, na Faculdade de Filosofia, Letras e Ciências Humanas (FFLCH) da Universidade de São Paulo (USP). A entrevista foi integralmente registrada em áudio e parcialmente em vídeo. Muitas das informações aqui compartilhadas foram recolhidas nessa entrevista, posteriormente transcrita, e que durou exatos 33 minutos. A divulgação desses dados foi autorizada por Emerson Alcalde, que assinou Termo de Consentimento Livre Esclarecido, conforme exigência do Comitê de Ética da UNICAMP.

4 MCs é o acrônimo de Mestre de Cerimônias (em inglês, Masters of Ceremony). No sentido amplo, trata-se de um apresentador de um evento; no sentido pretendido aqui, MCs refere-se aos artistas rappers que falam ou cantam suas músicas ao microfone enquanto são acompanhados pelos DJs (Disco-Jóqueis). Nos Estados Unidos, os MCs e os DJs são partes integrantes do movimento de hip hop, que envolve as performances corporais de dança (o break), os desenhos 
Nova York (nos EUA) quanto no Brasil acontecem nas estações de metrô. Ali, no meio da praça - sim, porque "A praça! A praça é do povo / Como o céu é do

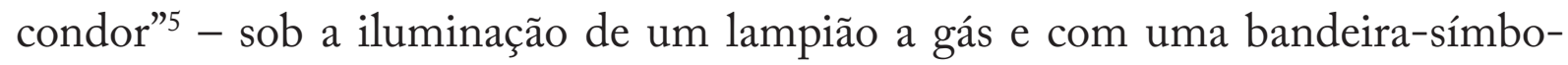
lo do slam estendida em uma árvore, reúnem-se em roda os organizadores do evento, o público, os jurados e os slammers para dar início às batalhas poéticas.

Entretanto, adverte-nos Marcello G. P. Stella (2015), ocupar um espaço público não é algo que se dá sem conflitos. O Slam da Guilhermina já sofreu reclamações dos comerciantes das redondezas e suspeitas dos seguranças do metrô próximo. Tampouco pacífica é a aceitação pelos cânones tradicionais dessa literatura marginal periférica, que cresce no Brasil no decorrer da década de 1990, e que rompe com a linguagem culta, valorizando os termos e as gírias das periferias. A literatura marginal provoca certo desconforto no campo literário nacional mais amplo, reconhece Stella (2015), uma vez que os sujeitos periféricos passam a reivindicar seu espaço e querem ser considerados escritores como quaisquer outros autores nacionais. É preciso legitimar essa nova voz, defende o autor, sem tratá-la como elemento exótico ou de valor estético inferior. "E quem há de negar que esta lhe é superior!" "

Tanto o ZAP! Slam quanto o Slam da Guilhermina chegam a reunir cerca de duzentas a trezentas pessoas desejosas de ouvir poesias declamadas e por isso têm que controlar o número de poetas inscritos para o evento: de quinze a vinte slammers por noite. Há, contudo, explica-nos Stella (2015) em sua pesquisa antropológica, o "público cativo", aquele que é frequentador habitual dos campeonatos de poesias, geralmente pessoas amigas dos poetas ou dos organizadores do evento, e que moram nas proximidades da região; e o "público passante", aquele formado por curiosos, pessoas que estão de passagem pela região - no caso do Slam da Guilhermina, pessoas que saem da estação de metrô ao lado da praça - e que decidem parar em torno do evento para escutar poesias.

de grafiteiros, as poesias cantadas (o rap) pelos rappers (ou MCs) e as músicas eletrônicas manipuladas pelos DJs.

5 Verso célebre do poema "O povo ao poder" (1864), de Castro Alves.

6 Referência à letra da música "Língua" (1984), de Caetano Veloso. 
Linha D'Água (Online), São Paulo, v. 30, n. 2, p. 92-112, out. 2017

\section{A hora e a vez dos Slams: de São Paulo a Paris}

Dos aedos e rapsodos da antiga Grécia, aos repentistas e cordelistas do Nordeste brasileiro, a poesia falada (spoken word) dos slams é hoje o fenômeno poético que se espalhou pela cidade de São Paulo e pelo Brasil. Alcalde arrisca dizer que, atualmente, a capital paulista já conta com, no mínimo, 25 slams, e que no Brasil somariam mais de 50 slams, aproximadamente. Dentre eles, os mais famosos são: ZAP! Slam, Slam da Guilhermina, Slam do 13, Slam da Ponta, Menor Slam do Mundo, Slam do Grito, Slam das Minas, Slam do Corpo, Slam Resistência, Slam Sófálá, Rachão Poético, todos em São Paulo; Rio Poetry Slam, no Rio de Janeiro, e Slam Clube da Luta, em Belo Horizonte.

Os campeonatos de poesias têm dez etapas ao longo do ano, pois acontecem de fevereiro a novembro, e em dezembro há o campeonato final, que reúne todos os ganhadores de cada mês, para definir quem será o vencedor anual daquele slam. Esse último é quem disputa o Campeonato Nacional de Slams (o Slam Br) com todos os outros campeões anuais de cada slam do país para definir o vencedor que vai representar o Brasil na Copa do Mundo de Poesia Falada, que ocorre todo ano em Paris, na França. Um mesmo poeta pode competir em mais de um slam desde que com poemas diferentes. Desse modo, se for vencedor, acaba eliminando a vaga de um ou outro poeta concorrente ao Slam Br e, por conseguinte, ao Campeonato Mundial.

$\mathrm{Na}$ França, são vinte slammers competindo, cada poeta representando seu respectivo país, e o evento dura uma semana de dezembro, no Téâtre Belleville de Paris. Tudo organizado e financiado pelo governo parisiense. Lá, a divulgação do evento na mídia é estrondosa: televisão, jornais, rádio, outdoors, cartazes no metrô - contou-nos Emerson Alcalde em entrevista - bem diferente do Brasil, em que a divulgação dos slams é ainda tímida. Algumas matérias já saíram na TV Globo e na TV Cultura, mas os jornais, de modo geral, ignoram os eventos. $\mathrm{Na}$ Copa do Mundo de Slam, a televisão francesa faz entrevistas com os poetas que vão participar do torneio e as matérias nos jornais chegam a ocupar uma página. Repercussão igualmente vista em Toronto, no Canadá, onde os slams são eventos reconhecidos e valorizados, explica-nos Alcalde, que já participou de slams lá, na Argentina, Venezuela, Caribe e em alguns países da África. 
Quando participou da Copa do Mundo, em 2014, Alcalde ficou impressionado com o envolvimento também das escolas francesas no evento, pois presenciou caravanas de crianças chegando ao teatro, com cartazes, gritos de torcida, muito empolgadas para compor o espetáculo como plateia.

Aqui no Brasil, os slams contam com pouca divulgação institucional ou estatal, mas com algum financiamento privado ou doações de simpatizantes da causa. Para participar do Campeonato Mundial, os poetas-slammers vencedores do Slam Br contam, por exemplo, com recursos do Itaú Cultural e do SESC (Serviço Social do Comércio), que pagam as passagens aéreas para Paris. Quanto à divulgação, diz-nos Alcalde, os organizadores a fazem por meio das redes sociais, sobretudo pelo facebook. Os eventos sempre são fotografados, filmados e gravados. As imagens circulam pelo Youtube e são compartilhadas e curtidas por milhares de pessoas em suas redes sociais. Com recursos próprios, o Slam da Guilhermina e do Sófálá conseguem publicar um livro por ano, reunindo as poesias vencedoras de cada mês.

Alcalde conta-nos, ainda em entrevista, que o Slam Resistência, fundado pelo poeta Del Chaves, em 2014, tornou-se um dos mais famosos graças à divulgação de seus vídeos na rede feita pelos próprios organizadores do evento, que não aceitam qualquer interferência midiática nem governamental, comportando-se como o slam mais radical nesse sentido. Quando a prefeitura demonstra interesse em cercar a praça Roosevelt, no centro de São Paulo, espaço de encontro do Slam Resistência todas as primeiras segundas-feiras de cada mês, o ato policial não é bem-vindo e os organizadores do slam resistem, literalmente. Del Chaves já chegou a enfrentar a tropa de choque com seu "ativismo poético", fato que terminou sem violência, já que no final "a poesia sempre vence" - costumam dizer os slammers. Entretanto, confessa Alcalde, esse enfrentamento não se dá nunca sem tensão de ambas as partes.

O objetivo final dos slams não é ganhar a fama midiática nem dinheiro com seus eventos, mas, paradoxalmente, de se fazerem ouvir, conclui Alcalde. Promover a poesia oral, falar poesias (spoken word), ler, escrever, declamar, divulgar, promover batalhas de performances poéticas, transformar os slams em linguagem, em educação - eis os desafios dos slammers ao/no mundo contemporâneo. Por isso, Alcalde, inspirado também no que testemunhou na França na ocasião da Copa do Mundo de Poesia Falada, teve a ideia de levar o slam para as escolas, organizando a partir de 2015, o 
Linha D'Água (Online), São Paulo, v. 30, n. 2, p. 92-112, out. 2017

Campeonato Interescolar de Slams em São Paulo. A seguir, a pesquisa de campo: o que vi, ouvi e vivi no slam por que passei e, por fim, a hora e a vez das poesias nas escolas: os campeonatos intra/interescolares de slams em São Paulo. Poesia é educação.

\section{Slam Sófálá - porque só a poesia nos une!}

Sábado, 20 de maio de 2017, início previsto às 16h, na Estação Red Bull Station ${ }^{7}$, na Praça da Bandeira, n. 137, no Centro de São Paulo.

A tarde fria não impediu que dezenas de jovens ocupassem o espaço da antiga estação desativada de energia de São Paulo para recitar e ouvir poesias. "Só a poesia nos une. Socialmente. Economicamente. Filosoficamente" no Oswald de Andrade, se ali estivesse, readaptando seu Manifesto Antropófago de 1928. Naquele ambiente hardcore, todos se sentiam devorados, deglutidos e mastigados por aqueles versos versados no início da Virada Cultural Paulista de 2017.

O mestre de cerimônia era Emerson Alcalde, já aqui citado, e conhecido por ser o fundador do famoso Slam da Guilhermina, na Zona Leste de São Paulo. Naquele dia Alcalde era o responsável por conduzir o Slam Sófálá, na Red Bull Station. No palco, ao microfone, o slammaster dá início ao evento apresentando-nos o DJ Victor Martins (conhecido como DJ Vitonez) e convidando o primeiro poeta para ir ao palco, sem que a batalha tivesse ainda começado. Vale dizer que faz parte do ritual do slam deixar o microfone aberto ao público, meia hora antes de começar a batalha, para quem desejar declamar seus poemas ou poemas alheios. Trata-se de um recital livre de poesias, espécie de aquecimento antes do campeonato. Nesse tempo inicial é que os poetas se inscrevem junto ao mestre de cerimônias para a batalha que virá em seguida. Um slammer aceita o convite de Alcalde e se apresenta,

7 Red Bull Station é um espaço no centro da cidade de São Paulo disponível para jovens artistas abrigarem seus projetos experimentais de ateliês, estúdios de música, mostras, shows e palestras. Todos os espaços são abertos para visitação, com acompanhamento de monitores. O prédio que ocupa foi construído em 1926 e era sede da antiga Eletropaulo. O novo espaço foi inaugurado em 2013. (Cf. em: <http://vejasp.abril.com.br/estabelecimento/red-bull- station/>. Acesso em 27 de maio de 2017)

8 Verso original: "Só a Antropofagia nos une. Socialmente. Economicamente. Filosoficamente". In: Revista de Antropofagia, maio de 1928.

NEVES, C. A. B. Slams - letramentos literários de reexistência ao/no mundo contemporâneo 
com seu filho pequeno agarrado, literalmente, na barra da sua calça. Abriu o evento declamando um poema-aperitivo que explorava os sentidos do verbo ser.

D’Alva (2014) explica-nos que há três regras básicas que regem todo e qualquer slam: "os poemas devem ser de autoria própria do poeta que vai apresentá-lo, deve ter no máximo três minutos e não devem ser utilizados figurinos, adereços, nem acompanhamento musical” (p. 113). Logo, a avaliação do júri deve levar em conta a performance poética do slammer ao incorporar o seu poema recitando-o - espécie de "autoperformance", nomeia a autora. Ou seja, não basta declamar o texto poético, é preciso dizer as poesias com as técnicas do corpo, diria Marcel Mauss ${ }^{9}$. Os slammers têm que se concentrar no corpo e na voz, já que não podem contar com subterfúgios cênicos em suas performances poéticas. Essas instruções são todas dadas e reforçadas aos cinco jurados na hora em que são selecionados aleatoriamente do público.

De acordo com Paul Zumthor (2007), a performance oral é também gestual, ritualística por excelência, exige a participação do corpo e pode se dar em "teatralidade" ou "espetacularidade", dependendo de sua percepção espacial. É daí que emana o prazer do texto (BARTHES, 2006), gozo da liberdade para quem lê (no caso do slam, para quem declama) com o corpo e para quem ouve com a alma. Ainda segundo Zumthor (2007), aquele que lê/declama em voz alta toca o outro pelas orelhas, e aquele que escuta é capturado pela melodia e pelo ritmo impressos no ato da leitura/declamação. Ao mesmo tempo em que nos lançamos ao outro que nos escuta, escutamos também a nós mesmos, ao nosso corpo, já que a voz, explica-nos o autor francês, é um corpo que se lança ao outro e retorna a si mesmo. A leitura/ declamação em voz alta implica, pois, corpo e alteridade: é endereçada ao outro, dinamizando língua/corpo e sujeito. Por isso Zumthor (2007) clama por uma poesia vocal, recitação que requer a presença constante do corpo, músculos, vísceras e sangue, lugar central e único modo vivo de comunicação poética - eis a performance.

Com efeito, nas formas poéticas transmitidas pela voz (ainda que elas tenham sido previamente compostas por escrito), a autonomia relativa do texto, em relação à obra, diminui muito: podemos supor que, no extremo, o efeito textual

9 Apropriei-me do título da obra de Marcel Mauss, Les techniques du corps (2006). 
desapareceria e que todo o lugar da obra se investiria dos elementos performanciais, não textuais, como a pessoa e jogo do intérprete, o auditório, as circunstâncias, o ambiente cultural e, em profundidade, as relações intersubjetivas, as relações entre a representação e o vivido. De todos os componentes da obra, uma poética escrita pode, em alguns casos, ser mais ou menos econômica; uma poética de voz não o pode jamais. (...) Estou particularmente convencido de que a ideia de performance deveria ser amplamente estendida; ela deveria englobar o conjunto de fatos que compreende, hoje em dia, a palavra recepção, mas relaciono-a (...) para uma percepção sensorial - um engajamento do corpo. (...) O termo e a ideia de performance tendem (...) a cobrir toda uma espécie de teatralidade: aí está um sinal. Toda "literatura" não é fundamentalmente teatro? (ZUMTHOR, 2007, p. $17-18$ - grifos do autor).

Para Zumthor (2007), o oral se torna uma urgência atual, uma espécie de retorno forçado ou revanche da voz humana contra a tecnologia dos media; uma necessidade de desestabilizar o curso hegemônico da escrita nas sociedades ocidentais - defende. Uma prática antiga que tem, ao mesmo tempo, "se perdido" e "se achado" na sociedade contemporânea. Os textos poéticos, as cantigas, as parlendas, as anedotas, todos jogam com a sonoridade de maneira significativa, criando novos sentidos não expressos pela língua normativa - daí o forte impacto, conclui-se, que as poesias exercem quando da sua escuta, pois o que está em jogo são as palavras, os sentidos, as onomatopeias, os ritmos, as melodias; gesto, corpo, língua, olhar e voz são despertados na cena poética em voz alta.

De volta às recitações performáticas do Slam Sófálá: aplausos, música do DJ e a escolha dos cinco jurados advindos do público. Começa a batalha. Ainda de acordo com as regras, um dos organizadores, chamado de counter, é quem fica encarregado de cronometrar o tempo de três minutos para cada apresentação, bem como de escrever as notas (de zero a dez) de cada slammer em uma planilha-controle e fazer a matemática do jogo. Quando ultrapassa o seu tempo-limite, o poeta é avisado pelo counter (na ocasião, a função foi atribuída a Uilian Chapéu), que levanta a mão fazendo-lhe um sinal, e então o slammer dispõe de mais dez segundos para encerrar.

Interessante atentar para os três minutos que cada poeta tem para declamação, pois isso exige cuidado especial dos slammers ao comporem seus poemas. Eles os escrevem pensando em dizê-los - e também em se dizerem - nesse tempo 
determinado. Na planilha, das cinco notas, a mais alta e a mais baixa são cortadas. Faz-se a média das três notas restantes. E então o rito se repete: às notas baixas a plateia grita "Credo!" e às notas altas ouve-se um "Bom!", com ritmo e cadência próprios. Nota-se um público ativamente envolvido com a cena poética.

Nesse sentido, pode-se dizer, na esteira da filosofia dialógica de Mikhail Bakhtin, que na performance poética do slam, o poeta age como locutor/falante interativo, o interlocutor/ouvinte como um leitor ativo, responsivo e replicante, e que as condições de recepção (a escuta) e de produção (a escrita) estão o todo tempo em jogo, isto é, são determinantes para a construção do gênero discursivo/ textual poético:

(...) o outro, ao perceber e compreender o significado (linguístico) do discurso, ocupa simultaneamente em relação a ele uma ativa posição responsiva: concorda ou discorda dele (total ou parcialmente), completa-o, aplica-o, prepara-se para usá-lo etc (...) Toda compreensão da fala viva, do enunciado vivo é de natureza ativamente responsiva (embora o grau desse ativismo seja bastante diverso); toda compreensão é prenhe de resposta, e nessa ou naquela forma a gera obrigatoriamente: o ouvinte se torna falante. (BAKHTIN, 2003, p. 271, grifos nossos)

Para o filósofo russo, o dialogismo está nessa interação pela linguagem que ocorre em um contexto em que todos os participantes (falante e ouvinte) são ativos e se encontram em condição de igualdade. Todo falante está determinado precisamente a essa compreensão ativamente responsiva do seu ouvinte. Ele espera, por assim dizer, uma resposta, uma concordância, uma participação, uma objeção, uma execução etc. No caso dos slams, essa resposta não se restringe às notas do júri, mas também, e principalmente, à reação do público ouvinte. Esse dialogismo está presente durante todo evento, até mesmo nos intervalos da batalha, quando o mestre de cerimônias anima a plateia com perguntas e respostas, conforme relato mais adiante, ou quando anuncia o grito do slam e o público o completa, em coro, como sinal ritualístico de cada retomada ao torneio.

Ademais, é possível associar o evento dos slams a uma verdadeira "arena" em que discursos poéticos se "digladiam", tal como imagem proposta por Bakhtin (2003). O clima de rivalidade é, contudo, amenizado pelos organizadores, que sempre emitem 
Linha D'Água (Online), São Paulo, v. 30, n. 2, p. 92-112, out. 2017

frases de consolação e motivação, do tipo: "aqui ninguém está acima de ninguém”; "o slam é um lugar de encontro democrático"; "ninguém sai daqui menos poeta, se perder"; "no fundo somos todos amigos"; "no slam no final a poesia é quem vence"; "a competição não é o que vale mais, não é quem ganha que importa, mas sim a poesia" etc. Tudo o que não vale de nada em se tratando de batalhas poéticas.

O slam é composto de três rodadas. $\mathrm{Na}$ primeira participam todos os poetas que se inscrevem, cinco vencedores vão para a segunda rodada e três competem na terceira. Dessa sai o slammer vencedor. Em caso de empate, somam-se as notas anteriores para definir o campeão, no caso, o slampião ou a slampia $\tilde{a}^{10}$. A primeira rodada do Slam Sófálá contava com quinze poetas inscritos. Momento único, como bem o descreveu o curador do evento:

Sentamos no sofá, na frente vemos apenas um único microfone, ao redor a rústica arquitetura do velho centro, um emissor aleatoriamente se desloca ao proscênio e fala, prestamos atenção, mergulhamos nas nossas profundezas, criamos asas, alçamos voos como águias, sentimos a brisa a cada analogia abordada abstraída do concreto, ao distanciarmos espacialmente do solo, girando ficando de pontacabeça sentindo adrenalina de ver o mundo sob outra ótica, um olhar não hegemônico, como se apertássemos a tecla sap e as palavras conhecidas passam a ter novos sentidos, é instaurado uma zona autônoma temporária, seguimos assistindo chorando sorrindo enquanto planamos. (ALCALDE, 2016a, s/n.) ${ }^{11}$

Corpo e voz, simultaneamente, dão o tom do espetáculo performático. Alguns poetas declamam no palco, alternando o uso ou não do microfone; outros caminham por entre a plateia, gesticulam, gritam e silenciam, incorporando os

10 Termos emprestados aqui do Manifesto do Slam da Guilhermina, em que se faz referência a Lampião e à Maria Bonita, daí os neologismos slampião e slampiã. No tal Manifesto, os slammers da Guilhermina se comparam aos cangaceiros nordestinos que desestabilizaram o sistema latifundiário e coronelista.

11 Notam-se, na descrição poetizada de Emerson Alcalde, imagens que nos remetem ao slogan "Red Bull te dá asas" bastante comum na publicidade do energético Red Bull, patrocinador do evento Sófálá. Se foi proposital ou não eu não sei, mas foi ao que imediatamente associei ao ler o "criamos asas, alçamos voos como águias", e mais adiante, "girando ficando de ponta-cabeça sentindo adrenalina de ver o mundo sob outra ótica", e ao final, "planamos". (CF. algumas dessas publicidades foram disponibilizadas em: <https://www.youtube.com/watch?$\mathrm{v}=\mathrm{n} 8$ _7EGNdpFE>. Acesso em 28 de maio de 2017). 
Linha D'Água (Online), São Paulo, v. 30, n. 2, p. 92-112, out. 2017

poemas igualmente de cor e par coeur ${ }^{12}$. Dois apenas preferiram ler em voz alta, em vez de recitar decorados seus poemas, com apoio de celulares e tablets disponíveis em suas mãos.

Nos intervalos, entre um slammer e outro, o DJ solta o som e Emerson Alcalde retoma o microfone para entreter o público. Faz perguntas aos espectadores e quem responder primeiro e corretamente ganha um livro de poesias: na ocasião, os brindes eram uma antologia poética dos ganhadores do Slam Sófálá em 2016, e o livro Slam da Guilhermina: três ponto zero, uma coletânea de poemas de 2015 do referido slam. A primeira pergunta-desafio lançada foi "quem escreveu o livro Quarto de despejo?", e a resposta veio de imediato: "Carolina de Jesus". Emerson não a aceitou como correta, até que alguém remendou: "Carolina Maria de Jesus" e ganhou o livro. Alcalde aproveitou-se da ocasião para falar da importância da autora mineira, mulher negra e pobre, que narra em seu livro histórias de dor e angústia vividas por ela em uma favela da cidade de São Paulo entre os anos de 1955 e 1960.

A segunda pergunta foi sobre a autoria de Vidas Secas, rapidamente respondida: "Graciliano Ramos". A terceira pergunta foi sobre um poeta moçambicano, autor de uma obra cujo título não foi registrado de modo audível. Alguém da plateia arriscou Mia Couto, mas não era. A resposta correta foi pronunciada, mas tampouco escutada. A quarta pergunta lançada ao público foi a mais interessante. $\mathrm{O}$ mestre de cerimônias perguntou se alguém sabia o título do livro de poesias escrito por Michel Temer e ouviu-se como resposta: "Anônima intimidade". A plateia era mais bem informada do que supunha nossa vã filosofia! Emerson Alcalde então decidiu mudar a pergunta para descontrair (e contrariar) um pouco mais os presentes e indagou "qual seria o título do livro a ser escrito sobre Michel Temer". Dentre as sugestões proferidas, venceu o célebre "Fora, Temer". Voltemos à batalha. Como sinal ritualístico para essa retomada, Alcalde diz ao microfone: "Sófá..." e os espectadores respondem: "Lá!"13

12 O termo em francês par coeur ("de coração") corresponde em português ao nosso "de cor". Aqui cabem as duas acepções, já que os slammers declamam os versos de cor e de coração.

13 Esse ritual varia a cada slam. No caso do Slam das Minas, por exemplo, o grito da organizadora para retomar a batalha é: "Slam das Minas!" - ao que o público responde: "Manas (ou monas ou minas), monstras!". Já no Slam Resistência, o slammaster enuncia: "Sabotagem sem massagem na mensagem!" - e o público replica: "Slam Resistência!". E então (re)começa mais 
De modo geral, no evento do Slam Sófálá os poemas declamados apresentavam, em sua totalidade, temas de teor crítico e engajado, exigindo reflexão e politização do seu público- ouvinte - poesias ideológicas e dialógicas, nos termos, mais uma vez, de Bakhtin (2003). Por meio de suas poesias orais e performáticas, as "vozes das margens" (HALL, 2003), as "vozes do Sul” (MOITA LOPES, 2006) e as "vozes do corpo" (DE CERTEAU, 1994) denunciavam, em versos rimados, as mazelas históricas que assolaram o Brasil desde o seu descobrimento. Críticas políticas que revisitaram a nossa colonização, relembraram a ditadura militar de 1964, passando pela ação da lava-jato e pelo impeachment da presidente Dilma; acusaram de golpe Michel Temer e debocharam do vício de Aécio Neves; críticas às desigualdades sociais, ao preconceito racial, à violência contra a mulher, à homofobia, à transfobia; em defesa de políticas afirmativas, como a inclusão das cotas nas universidades. Poesias marginais que versificam não apenas a periferia, mas todo o Brasil. Nas palavras de Alcalde, "Slam não é tribunal, traduz a sociedade, (...) o protagonismo é dos desfavorecidos” (2016a, s/n.)

Fim da primeira rodada. Luíza Romão e Daniel Carvalho gabaritaram com dez na avaliação dos cinco jurados. Participarão da segunda rodada e, com certeza, da final daquela batalha poética. Os dois merecem atenção, uma vez que seus versos continuaram ecoando, mesmo após o evento - foi o meu primeiro alumbramento! ${ }^{14}$. Incorporaram poesias que impactaram a plateia, deixaram-na em absoluto êxtase, em estado de catarse. Vale a pena conferir as performances poéticas de cada um em Relatos de um país-fálico e Contos de farsas ${ }^{15}$, respectivamente. Luíza Romão é poeta, atriz e diretora de teatro. Formou-se em Direção Teatral na ECA -USP em 2014 e, atualmente, estuda na Escola de Artes Dramática. Participou da Cia Ato Reverso e do grupo de Teatro Documentário. Hoje é atriz convidada no Núcleo Bartolomeu de Depoimentos e integrante do coletivo de performance da palavra Literatura Ostentação. Publicou o livro Coquetel Molotove, em 2014, e já

uma performance poética.

14 Tomo emprestado o verso de Manuel Bandeira em "Evocação do Recife".

15 A performance poética de Luíza Romão está disponível em <https://www.youtube.com/ watch? $v=s 73 G o R-P T c Y>$. Acesso em 05 de junho de 2017. Já a de Daniel GTR encontra-se disponível em

<https://www.youtube.com/watch?v=02EnVYo77RU>. Acesso em 05 de junho de 2017. 
Linha D'Água (Online), São Paulo, v. 30, n. 2, p. 92-112, out. 2017

participou de inúmeros slams: foi campeã do Slam do 13, do Slam da Guilhermina e vice-campeã nacional do Slam $B R$.

Daniel Carvalho (conhecido como Daniel GTR) é músico, educador, poeta e morador da COHAB I, na Zona Leste de São Paulo. De 2013 a 2016, desenvolveu o projeto "Arte e Intervenção Social", o qual recebeu três premiações no "Prêmio Paulo Freire de Qualidade de Ensino Municipal: o $3^{\circ}$ lugar em 2014 e o $1^{\circ}$ lugar em 2015 e 2016. Durante a realização desse projeto, Daniel organizou duas obras literárias em parceria com seus alunos, principais incentivadores do poeta, a saber: Entre versos controversos e Entre versos controversos: o canto de Itaquera (vol. II). Seu investimento na literatura marginal não parou por aí. Ele participa ativamente dos slams da cidade, além de ser um dos fundadores do projeto de poesia periférica "Poesia na Laje". Daniel defende que tais eventos culturais garantem o empoderamento das classes minoritárias e estigmatizadas, dão voz aos emudecidos pelo sistema, valorizam a arte popular, marginal, periférica, funcionam como resistência político-ideológica fortalecendo seu éthos - são, portanto, letramentos de reexistência, no neologismo de Ana Lúcia S. Souza (2011), quando a autora se refere aos raps. Tomo o termo emprestado no título deste artigo estendendo-o para as batalhas poéticas dos slams.

Como se vê, as poesias (sobre)vivem (às) nas ruas, circulam pelas estações, ocupam as praças e, felizmente, invadem as escolas por meio de iniciativas como a de Daniel GTR e como a de Emerson Alcalde, idealizador dos Campeonatos Interescolares de Slams em São Paulo. Poesia é preciso.

\section{Entre os muros da escola ${ }^{16}$ : Slams intra/interescolares de São Paulo}

Poetas, gritos, artistas de rua,

Fazemos poesias como jogamos bola,

Para democratizar a literatura,

Levamos os Slam para as escolas... (Emerson Alcalde, 2016)

16 Expressão que nos remete ao filme francês Entre les murs, traduzido para o Brasil como Entre os muros da Escola, do cineasta Laurent Cantet, Palma de Ouro em Cannes, 2008. 
Linha D'Água (Online), São Paulo, v. 30, n. 2, p. 92-112, out. 2017

Alcalde (2016) relata-nos que a ideia de levar o slam para as escolas surgiu na França, na ocasião da Copa do Mundo de Slam, em 2014, quando o poeta assistiu a um slam entre escolas no Téâtre Belleville de Paris. Alcalde logo se envolveu com o evento, ajudando a colar cartazes e a preparar o espaço do teatro para receber as crianças que desembarcavam em verdadeiras caravanas, de ônibus, metrôs e trens, advindas de diversas cidades da França. Ao voltar ao Brasil, ele propôs ao Slam da Guilhermina organizar um campeonato de poesias entre as escolas de São Paulo, tal qual viu na capital francesa.

Em 2015, Alcalde sondou as escolas das redondezas, Zona Leste de São Paulo, e conseguiu adesão de quatro escolas: a E. E. Prof. Gabriel Ortiz, o CEU Três Pontes, a EMEF Cláudio Manuel da Costa e o Colégio La Salle. Então promoveu workshops, ministrou palestras falando a respeito do surgimento dos saraus periféricos e dos slams de poesias, ofereceu oficinas de escritas poéticas, mostrou vídeos de eventos dos slams, enfim, tudo pensado para envolver professores e incentivar alunos e então organizar o Primeiro Slam Interescolar de São Paulo. Em 2016, o Segundo Slam Interescolar contou com vinte escolas, sendo dezenove públicas (estaduais e municipais) e uma particular. A perspectiva é que em 2017 a adesão das escolas seja maior ainda ${ }^{17}$ - otimizam Alcalde e Cristina Assunção, também organizadora dos Slams Interescolares de São Paulo.

O processo, contudo, obedeceu a etapas. Ainda em 2015, quando Alcalde era coordenador de cultura do Centro Educacional Unificado Três Pontes (CEU Três Pontes), teve a ideia de realizar um Slam Intersalas - ou um Slam Intraescolar, pode-se assim dizer. Sua presença diária na escola facilitava levar adiante esse projeto, além de contar com a colaboração de professores e coordenadores. Alcalde reuniu os alunos dos $4^{\circ}$ e $5^{\circ}$ anos do Ensino Fundamental I no Teatro do CEU para dar palestras e oficinas de escrita de poesias. Orientou os professores para continuar com o trabalho em sala de aula. Depois realizou um Slam Intersalas de onde saíram duas representantes vencedoras para o Slam Interescolar.

17 As inscrições para o Terceiro Slam Interescolar de 2017 se iniciaram em 31 de agosto e se encerram em 15 de setembro. Segundo Alcalde, principal organizador do evento, o saldo este ano foi de 42 escolas inscritas.

NEVES, C. A. B. Slams - letramentos literários de reexistência ao/no mundo contemporâneo 
Linha D'Água (Online), São Paulo, v. 30, n. 2, p. 92-112, out. 2017

Em 2014, em Paris, Alcalde conheceu a professora do SESC Itaquera, Carolina Andrade, e com ela encabeçou outro projeto visando ao slam-educação. No Brasil, realizaram um slam na BIBLIOSESC: um caminhão do SESC repleto de livros que circula pelos bairros periféricos de São Paulo oferecendo leitura a todos $^{18}$. O projeto contemplou cinco instituições da Zona Leste, portanto, foram cinco encontros com as turmas de alunos envolvidos. Alcalde ministrou oficinas de poesias escritas e faladas, ressaltando o aspecto performático como nuclear nos slams. Cada escola realizou a sua batalha poética e os vencedores se enfrentaram depois em uma final promovida no SESC Itaquera. A experiência foi assim descrita pelo poeta-slammer:

Levei Os miseráveis, de Sérgio Vaz, intercalando o Intertexto, de Brecht, junto com $E$ agora, Jose? ${ }^{19}$ de Drummond, e $A$ Massa, de minha autoria. Em grupo, a atividade era elaborar uma apresentação cênica desses textos, dividindo as falas, pensando no ritmo, intenções, pausas e a disposição no espaço. Observando a postura, o modo de colocar a voz e até mesmo a escrita, ficava nítida a influência dos slammers que passaram pelo espaço. Apresentei ainda exercícios de escrita dadaísta e depoimento pessoal. Eles até criaram poemas autorais colaborativos. Saíram textos lindos, outros tristes. (ALCALDE, 2016, p. 8-9)

Como bem conclui Alcalde (2016, p. 10): "É preciso mostrar poetas para além dos livros didáticos. (...) É preciso trazer a poesia para a oralidade, para o corpo, para a atualidade". O entusiasmo do professor-poeta é contagiante e sua aula de slam mereceria tanta atenção quanto aquela dada, por exemplo, aos ateliês de poemas descritos por Josette Jolibert $(1994,1994 \mathrm{a})$, ou às experiências com os diários de bordo ou com as autobiografias de leitores relatadas por Annie Rouxel

18 Isso muito me lembrou o que fez Mário de Andrade, de 1935 a 1938, quando chefiou o Departamento de Cultura da cidade de São Paulo e organizou a cultura com vistas ao público mais popular. Remodelou a Biblioteca Municipal - hoje Biblioteca Mário de Andrade - e levou bibliotecas ambulantes, em furgões, para diversos bairros mais pobres; criou uma discoteca pública, promoveu concertos, orquestra sinfônica, corais, enfim, diversos eventos musicais. Além disso, investiu em pesquisa folclórica e etnográfica, valorizando assim, as culturas populares. (Cf. em CANDIDO, Antonio. O direito à literatura. In: Vários escritos. 3. ed. São Paulo: Duas Cidades, 1995).

19 O poema de Carlos Drummond de Andrade se chama José, mas muitos se referem a ele como "E agora, José?" devido à fama do verso que se repete ao longo do poema. 
Linha D'Água (Online), São Paulo, v. 30, n. 2, p. 92-112, out. 2017

(2013) - para citar duas autoras francesas; bem como às oficinas de poesias descritas por Ana Elvira L. Gebara (2009), ou às sugestões de trabalho com leitura de poesias relatados por Hélder Pinheiro (2007) - para citar autores brasileiros.

Duas experiências, em especial, chamaram atenção de Alcalde (2016): uma no CCA Santa Marcelina de Itaquera, instituição coordenada por freiras, e outra na EMEF Fernando Azevedo, na Vila Curuçá. Na primeira escola, o slammer ofereceu oficinas poéticas para uma turma fechada, porém com salas de aula bastante heterogêneas em idades e graus de instrução. Todos eram protagonistas de vidas sofridas com famílias desestruturadas, relata-nos o poeta, e apresentavam muita dificuldade na escrita. Mesmo assim, a adesão dos alunos foi quase unânime e produziram poesias criativas e subjetivas. Na segunda escola, as oficinas de escritas poéticas aconteceram na sala de leitura e os alunos escolhidos pela professora para participar foram aqueles que mais emprestavam livros da biblioteca para ler. Alguns demonstravam habilidade com a escrita e já escreviam blogs, contos e eram fãs da série de livros de Percy Jackson, escrita por Rick Riordan, relata-nos Alcalde (2016).

Cristina Assunção, também organizadora do Slam Interescolar de São Paulo, conta-nos com igual entusiasmo sua experiência de "fazer da poesia um esporte!" (ASSUNÇÃO, 2016, p. 15). Em 2015, a professora realizou o SlamSalle: o slam no Colégio La Salle, instituição da rede privada de ensino, de ordem religiosa, onde ela leciona. Os campeonatos aconteceram uma vez por mês e envolveram a todos na escola, relata-nos a autora. A professora de Geografia ajudou na organização, a de Matemática foi a counter responsável pela soma das notas, outros cinco professores compuseram o júri e os alunos formaram a plateia de torcedores. A final do SlamSalle foi, para imitar o modelo parisiense, no Teatro Flávio Império, em Cangaíba - um verdadeiro événemment poétique - para usar a expressão no sentido empregado por Nathalie B. Rannou (2010). As duas vencedoras disputaram o Primeiro Slam Interescolar de São Paulo, competindo com os slampeões das outras três escolas participantes.

\section{Considerações Finais}

Os poemas produzidos pelas crianças nesses campeonatos intra/interescolares não foram disponibilizados em rede como os versos de Luiza Romão e Daniel GTR 
citados anteriormente. Contudo, embora não tenhamos acesso aos versos dos educandos, vale ressaltar que a própria ideia de levar os slams para as escolas já é um ato de ruptura, uma vez que a poesia da periferia adentra os muros escolares e ganha novos adeptos - "É feia. Mas é uma flor. Furou o asfalto, o tédio, o nojo e o ódio" ${ }^{20}$. Os alunos se tornam leitores e escritores de poemas, seus versos tematizam criticamente a atualidade, reivindicam mudanças - tal como requer o letramento ideológico defendido por Brian V. Street (2014) - em verdadeiro exercício de cidadania: poesia- educação; poesia-resistência - não necessariamente nessa ordem.

E a resistência faz parte do ser da poesia, explica-nos Alfredo Bosi, em seu belíssimo ensaio Poesia-resistência (2000). Para o autor, não há uma poesia-ingênua, há sim, uma poesia- resistência, fazendo-se, de algum modo e sempre, um discurso contraideológico - mais uma vez, ecos bakhtinianos (2003). De acordo com Bosi (2000), toda poesia moderna a partir do Pré-Romantismo é uma forma de resistência simbólica aos discursos dominantes. E a resistência tem muitas faces, ora propõe a recuperação do sentido comunitário perdido (poesia mitica, poesia da natureza); ora propõe a melodia dos afetos em defensiva (lirismo de confissão); ora propõe a crítica direta ou velada da desordem estabelecida (vertente da sátira, da paródia, do epos revolucionário, da utopia). Nostálgica, crítica ou utópica, a poesia moderna trilhou vários caminhos de resistência: poesia-metalinguagem, poesia-mito, poesia-biografia, poesia-sátira, poesia-utopia. Isso posto, não há como não defender a poesia dentro e fora das escolas - eis a nossa utopia.

Língua e corpo de alunos da periferia de São Paulo se juntaram, por meio dos slams intra/interescolares, para sustentar práticas de letramentos situadas e marcadas pela resistência e subversão - seus modos de existir. As escolas que, via de regra, silenciam essas vozes, começaram, ainda que timidamente, a lhes dar ouvidos. São, afinal, modos de versar não autorizados, desvalorizados, rejeitados porque ecoam uma cultura jovem, popular, negra e pobre, de moradores da periferia, bem diferentes do gosto canônico, branco e de classe média.

Alunos-slammers transgridem, portanto, a cultura legitimada pela instituição escolar, atuam como agentes de letramentos de reexistência, e não somente de

20 Verso final de "A flor e a náusea", de Carlos Drummond de Andrade.

NEVES, C. A. B. Slams - letramentos literários de reexistência ao/no mundo contemporâneo 
Linha D'Água (Online), São Paulo, v. 30, n. 2, p. 92-112, out. 2017

"resistência", explica-nos Souza (2011), pois não deixam de valorizar a cultura letrada escolar, mas principalmente a reinventam, a reformulam, a redizem, imprimindo nela sua identidade social e cultural. Ali, em versos, os alunos-slammers reagem, rejeitam, revoltam-se, reconhecem-se, resistem e restam. É preciso resistir para existir. Poesia é reexistência. Cabe à escola aceitar o novo desafio e se abrir à nova poesia do/no mundo contemporâneo. À nós, antes de tudo, e acima de tudo, resta-nos: as poesias; resta-poesia, res-poesia.

\section{Referências}

ALCALDE, Emerson. Slam na Educação: a poesia escrita com giz e dita com o coração. In: ALCALDE, Emerson; ASSUNÇÃO, Cristina; MOTTA, Rodrigo; CHAPÉU, Uilian (Orgs.). Slam da Guilhermina: três ponto zero. 1.ed., São Paulo: 2016.

ALCALDE, Emerson. Criando Asas. In: Sófálá, São Paulo: 2016a.

ALVES, Castro. O povo ao poder. In: Poesias Completas.17.ed. Rio de Janeiro: Ediouro, 1995, p. 216.

ANDRADE, Carlos Drummond de. A flor e a náusea. In: A rosa do povo. 31.ed. Rio de Janeiro: Record, 2006, p. 27.

ASSUNÇÃO, Cristina. Slam Salle: a práxis literária aproximando os jovens da poesia. In: ALCALDE, Emerson; ASSUNÇÃO, Cristina; MOTTA, Rodrigo; CHAPÉU, Uilian (Orgs.). Slam da Guilhermina: três ponto zero. São Paulo: 2016.

BANDEIRA, Manuel. Evocação do Recife. In: Poesia completa e prosa. Rio de Janeiro: Editora Nova Aguilar, 1985, p. 54.

BAKHTIN, Mikhail. Os gêneros do discurso. In: Estética da criação verbal. Introd. e trad. do russo: Paulo Bezerra; prefácio à edição francesa Tzvetan Todorov. 4.ed. São Paulo: Martins Fontes, 2003.

BARTHES, Roland. O prazer do texto. Trad. de Jacob Guinsburg. São Paulo: Perspectiva, 2006.

BOSI, Alfredo. Poesia-resistência. In: O ser e o tempo da poesia. São Paulo: Companhia das Letras, 2000. 
Linha D'Água (Online), São Paulo, v. 30, n. 2, p. 92-112, out. 2017

CANDIDO, Antonio. O direito à literatura. In: Vários escritos. 3.ed. São Paulo: Duas Cidades, 1995.

D’ALVA, Roberta Estrela. Teatro hip-hop: a performance poética do ator-MC. São Paulo: Perspectiva, 2014.

DE CERTEAU, Michel. A invenção do cotidiano: artes de fazer. Petrópolis: Vozes, 1994.

GEBARA, Ana Elvira Luciano. O ensino singular dos gêneros poéticos - reflexões e propostas. 2009.268p. Tese (Doutorado em Letras clássicas e vernáculas) - Faculdade de Filosofia, Letras e Ciências Humanas, Universidade de São Paulo, São Paulo, 2009.

HALL, Stuart. A identidade cultural na pós-modernidade. Trad. Tomás Tadeu da Silva, Guacira Lopes Louro. 11.ed., 1. reimp., Rio de Janeiro: SP\&A, 2011.

JOLIBERT, Josette. (Coord.) Formando crianças leitoras. Trad. Bruno C. Magne. vol. I., Porto Alegre: Arte Médicas, 1994.

JOLIBERT, Josette. (Coord.) Formando crianças produtoras de texto. Trad. Walkiria M. F. Settineri e Bruno C. Magne. vol. II., Porto Alegre: Arte Médicas, 1994a.

MOITA LOPES, Luiz Paulo da. (Org.). Por uma linguística aplicada INdisciplinar. São Paulo: Parábola Editorial, 2006.

MAUSS, Marcel. Les techniques du corps. In: Sociologie et anthropologie. 11.ed., Paris: Quadrige, 2006.

NEVES, Cynthia Agra de Brito. A literatura no ensino médio: os gêneros poéticos em travessia no Brasil e na França. 2014. 884p. Tese (Doutorado em Linguística Aplicada) - Instituto de Estudos da Linguagem, Universidade Estadual de Campinas, Campinas, 2014.

PINHEIRO, Hélder. Poesia na sala de aula. Campina Grande: Bagagem, 2007.

RANNOU, Nathalie Brillant. Le Lecteur et son poème. Lire en poésie: experience littéraire et enjeux pour l'enseignement du français en lycée, thèse de doctorat présentée à la faculté des Arts, Lettres, Langues de l'Université de Rennes 2, 2010.

NEVES, C. A. B. Slams - letramentos literários de reexistência ao/no mundo contemporâneo 
Linha D'Água (Online), São Paulo, v. 30, n. 2, p. 92-112, out. 2017

ROUXEL, Annie.; LANGLADE, Gérard.; REZENDE, Neide Luzia de. (Orgs.) Leitura subjetiva e ensino de literatura. Trad. Amaury C. Moraes et al; coord. e rev. Neide Luzia de Rezende; Rita Jover-Faleiros. São Paulo: Alameda Casa Editorial, 2013.

SOUZA, Ana Lúcia Silva. Letramentos de reexistência: poesia, grafite, música, dança: hip-hop. São Paulo: Parábola Editorial, 2011.

STELLA, Marcello Giovanni Pocai. A batalha da poesia: o slam da Guilhermina e os campeonatos de poesia falada em São Paulo. In: Ponto Urbe - Revista do núcleo de antropologia urbana da USP. São Paulo, 2015.

STREET, Brian V. Letramentos sociais: abordagens críticas do letramento no desenvolvimento, na etnografia e na educação. Trad. Marcos Bagno. São Paulo: Parábola, 2014.

ZUMTHOR, Paul. Performance, recep̧ão, leitura. Trad. Jerusa Pires Ferreira e Suely Fenerich. São Paulo: Cosac Naify, 2007.

Recebido em 19/07/2017.

Aprovado em 27/08/2017. 